\title{
EN TORNO AL CONFLICTO ENTRE DERECHOS: LA VISIÓN DE WALDRON Natalia Villalpando*
}

RESUMEN: Este ensayo apoya la aproximación de Waldron al conflicto entre derechos al mostrar cómo su postura conduce a lo que Kant compele a hacer a toda persona: ponderar activamente las situaciones de forma que sea posible reconocer las sutiles diferencias, en vez de aceptarlas como algo definitivo.

PALABRAS ClAVE: Jeremy Waldron, conflicto entre derechos, postura jerárquica, "red" de derechos, "efecto-ola".
ABSTRACT: This article supports Waldron's position on conflicts of rights by detailing how his stance is related to what Kant compels each person to do, namely reflecting actively on situations thereby recognizing the subtle differences among them instead of accepting them as given.

KEYWORDS: Jeremy Waldron, conflict of rights, hierarchical position, "system" of rights, "ripple effect."
RECEPCIÓN: 27 de octubre de 2011.

ACEPTACIÓN: 20 de noviembre de 2012.
* Candidata a Maestra en Filosofía y políticas públicas, London School of Economics and Political Science. 
¿ómo podemos determinar si prevalecer sobre el derecho que tiene un bebé a nacer? Son comunes las situaciones en que se produce un conflicto entre derechos y no queda clara cuál sea la mejor aproximación para resolverlos. Los problemas en que existe un conflicto entre derechos son de naturaleza muy variada; por ejemplo, toda persona debe tener el derecho a la seguridad pública y el derecho a la privacidad, pero ¿cómo podemos definir las circunstancias bajo las cuales el espionaje y los "escuchas" podrían justificarse? La búsqueda de soluciones a los problemas de conflicto entre derechos pueden comenzar por el reconocimiento de que las libertades persona-

\footnotetext{
* Traducción de Mauricio López Noriega.
}

les se hallan restringidas, tanto por las responsabilidades individuales, como por lo que atañe a la vida en común. Sin embargo, encontrar soluciones verdaderamente razonables para esta clase de dilemas requiere del profundo análisis de cada situación particular y de una cuidadosa evaluación de nuestra concepción de los derechos.

Este ensayo se basa en la aproximación de Jeremy Waldron ${ }^{1}$ al conflicto entre derechos, ya que el filósofo neozelandés muestra cómo su postura conduce a lo que Kant compele a hacer a toda persona: ponderar activamente las situaciones, para que sea posible reconocer sus sutiles diferen-

${ }^{1}$ A partir de Jeremy Waldron, "Rights in Conflict”, Ethics, 99, 1989; y “Theoretical Foundations of Liberalism", The Philosophical Quarterly, vol. 37, núm. 147, abril de 1987. 
cias, en vez de aceptarlas como algo definitivo. $^{2}$

También analizaremos una postura contraria a la aproximación de Waldron; nos referiremos a ella como la "postura jerárquica". ${ }^{3}$ Ésta parece simplificar lo que significa dar con una solución a los problemas de conflicto entre derechos, pues sugiere que cada derecho tiene un deber correspondiente; no obstante, argumentaremos que dicha aproximación tiende a limitar el pensamiento innovador y puede generar problemas adicionales. El ensayo se divide en dos partes: la primera presenta la postura jerárquica y analiza las consecuencias de confiar únicamente en ella cuando se trata de solucionar conflictos entre derechos; la segunda parte muestra las ventajas de utilizar la postura de Waldron al demostrar su superioridad sobre la postura contraria.

La postura jerárquica mira a los derechos y deberes como las dos caras de la misma moneda. Para cada derecho que exista puede encontrarse un deber que funcione como su justificación; por ejemplo, una persona tiene como deber "no matar": por consiguiente, otra persona tiene derecho a la vida. Esta interpretación

${ }^{2}$ Cfr. Emmanuel Kant, Filosofía de la Historia. Qué es la Ilustración, 2004, La Plata, Terramar Ediciones, col. Caronte Filosofía, trad. de Emilio Estiú y Lorenzo Novacassa.

${ }^{3}$ A partir de la postura de Onora O'Neill en torno a los derechos y al hablar sobre deberes. de "derechos versus deberes" supone que cualquier persona puede determinar qué deber sustenta qué derecho, al identificar y priorizar los deberes resultantes. Así, la postura jerárquica ofrece una solución aparentemente sencilla a los problemas de conflicto entre derechos: identificar los deberes, encontrar sus derechos correspondientes y determinar qué derecho puede ser comprometido y cuál tiene prioridad y debe ser respetado. La asunción previa detrás de la postura jerárquica es que existe una jerarquía fija de deberes que, una vez identificados, ayudan a encontrar soluciones cuando los derechos entran en conflicto.

La postura jerárquica implica que los deberes pueden ser clasificados en orden de importancia y que, subsecuentemente, la correspondencia uno a uno con los derechos puede utilizarse para determinar qué derecho es el más valioso y, por tanto, debe prevalecer. Queda implícito el pensamiento de que la gente sabe qué valoran más. De cualquier forma, esta manera simplista de pensar subestima dos aspectos importantes, que deben ser considerados cuando se analizan problemas de conflicto entre derechos: primero, el contexto, y luego, la importancia de innovar.

Analizar el contexto de un conflicto entre derechos es de suma importancia, pues éste puede modificar el 
valor real de los derechos que, por otro lado, podrían parecer fáciles de clasificar jerárquicamente. La Historia nos ofrece una amplia gama de ejemplos que ilustran cómo el contexto ha alterado la importancia inmediata de un derecho. Por ejemplo, las bien conocidas huelgas de hambre en la India y en Sudáfrica han mostrado que, bajo circunstancias extraordinarias de opresión e injusticia, un derecho aparentemente fundamental como tener acceso a la comida puede volverse temporalmente menos valioso que el derecho a la libertad. Tales fueron los casos de las huelgas de hambre de prisioneros políticos como Mahatma Gandhi y Nelson Rolihlahla Mandela.

Asimismo, innovar tiene una importancia extrema en la resolución de 194 problemas de conflicto entre derechos, porque permite identificar las mejores soluciones al promover un análisis abierto, desde varias perspectivas y con argumentos contrarios. Así, se vuelve alcanzable una solución más integral para antiguos problemas. Cuando no se toman en cuenta ni el contexto del problema ni la innovación en la búsqueda de soluciones, la eficiencia y la sencillez se vuelven demasiado valiosas y, más allá, no se promueve la reflexión. Cabe destacar que la eficiencia no se contrapone a la reflexión, como tampoco el pensamiento necesita tornarse complicado. La posición jerárquica fija un criterio que, aparentemente, siempre resulta claro y resolver derechos en conflicto se convierte en un procedimiento que ignora tanto el contexto como las experiencias anteriores y los futuros proyectos. $\mathrm{Al}$ basarse únicamente en la postura jerárquica, se ignora la necesidad de re-pensar los modernos problemas de conflicto entre derechos y la concepción de nuevas soluciones se hace menos probable.

Hemos descrito las consecuencias de fundamentarse sólo en la postura jerárquica cuando se enfrentan situaciones en que se producen conflictos entre derechos. En los siguientes párrafos se analiza la postura de Jeremy Waldron y se explica por qué su perspectiva promueve la reflexión.

Waldron concibe a los derechos como entidades apoyadas en múltiples deberes, intereses y valores. Por ello, cuando se presenta un problema de conflicto entre derechos, ${ }^{4}$ nadie puede, simplemente, relacionar un derecho con un deber. La relación entre derechos y deberes dejó de ser uno a uno. Esta forma de pensar conduce a la conceptualización de dichas relaciones como una "red", en la cual un derecho debe ser analizado en términos de su relación con muchos de-

${ }^{4}$ Por motivos de espacio no justificaré aquí por qué los derechos entran en conflicto, y confiar en la experiencia será suficiente para mostrar que el conflicto entre derechos surge siempre. 
beres e intereses que, a su vez, están relacionados con otros derechos y deberes. Además, es importante enfatizar que la existencia de la "red" de derechos de Waldron implica que el valor y la importancia del derecho están siempre relacionados con sus conexiones con otros derechos, deberes e intereses dentro de la "red". La comprensión de un derecho está mediada por la comprensión de su relación con la "red". En otras palabras, el significado de un derecho está determinado no por un deber aislado, como en la postura jerárquica, sino por el lugar que ocupa dentro de la "red". La mediación implica una exclusión que otorga determinación a cada una de sus partes, lo cual implica también cierto holismo: la forma en que los derechos son concebidos depende de su relación con lo demás. ${ }^{5}$

Para comprender cabalmente un derecho, se deben entender también los niveles primario y secundario del orden de las conexiones con la "red". Estas concatenaciones crean lo que Waldron llama el "efecto-ola", ${ }^{6}$ en el que un derecho o interés no puede ser satisfecho por un único deber. Claramente, la posición jerárquica no comparte las complejidades del "efecto-ola"; empero, la existencia de

${ }^{5} \mathrm{Cfr}$ : Robert Brandom, The Tales of the Mighty Dead, 2002, Cambridge, Harvard University Press, p. 198.

${ }^{6} \mathrm{Cfr}$. Waldron, "Rights in Conflict", op. cit., p. 510 . este efecto permite al interés individual estimular el respeto por los derechos de otras personas. Por ejemplo, el derecho que una jovencita tiene a desarrollarse intelectualmente genera un deber, por parte del gobierno, de proveer de un sistema educacional y otro deber, por parte de sus padres, de cuidar de sus salud física y mental, de modo que ella consiga educarse.

El derecho a la propiedad sirve también para ilustrar la complejidad del "efecto-ola" de los derechos, deberes e intereses de una persona. Primero que nada, encontramos que el derecho a la propiedad no tiene una correspondencia clara con un único deber; incluso si se debiera hallar alguno, seguiría resultando insuficiente para explicar a cabalidad el derecho a la propiedad: el deber de respetar a los otros puede intentar la justificación de dicho derecho; sin embargo, el deber de respetar a los demás no necesariamente conlleva el respeto por su propiedad. Para entender acabadamente el derecho a la propiedad podemos servirnos de la visión de Waldron y comenzar por el análisis de las relaciones particulares que dicho derecho mantiene con otros intereses, deberes y derechos. En primer lugar, toda persona tiene interés en ser propietaria de las cosas que le resultan importantes para su bienestar, por decir, una casa limpia; en segundo, el deber de 
una persona de respetar a los otros genera una ola de deberes dentro de la "red". Se esperaría que una persona que realmente respeta a los otros respete también las ideas, el trabajo y las propiedades que han sido obtenidas con el producto del trabajo. En tercer lugar, el derecho a la propiedad está relacionado con otros derechos, como el derecho a trabajar, a educarse y a desarrollarse personal y profesionalmente. Una vez identificadas las relaciones del derecho a la propiedad con otros intereses, deberes y derechos, es posible introducir ahora un contexto particular y determinar el valor real del derecho a la propiedad dentro de dicho contexto.

Por último, al mostrar la complejidad de la comprensión del conflicto entre derechos, Waldron busca que la gente adquiera un conocimiento profundo del contexto de los problemas e invita a pensar de manera creativa con miras a encontrar la mejor solución. Si se acepta que no existe una medida única que pueda ser apli cada, indiscriminadamente, a todos los problemas de conflicto entre derechos, la postura de Waldron promueve la reflexión continua y la innovación, y espera que la gente justifique por qué cada conflicto debe ser tratado de determinada manera. Es más probable que una aproximación tan abierta resuelva situaciones de conflicto entre derechos porque brinda las mejores condiciones para reflexionar, para entrar en discusión y -más importante- para disentir con ciertos puntos de vista. La postura de Waldron es más efectiva que la postura jerárquica porque provee de un marco referencial que ayuda a generar soluciones, sin imponer límites al análisis de los problemas. La naturaleza de los problemas de conflicto entre derechos evoluciona de la mano de la civilización humana; por ello, nuestros marcos de referencia en la solución de dichos conflictos debe ser flexible y capaz de adaptarse al continuo cambio de la naturaleza del problema. 